\title{
A month at the Shanghai Library, November 2004
}

\author{
Helen Michael
}

\section{Introduction}

In November 2004, I spent a month working in China at the Shanghai Library, at the invitation of its director, Dr. Wu Jianzhong. This was a very interesting experience for me, and I am forever grateful to the University of Toronto for making the trip a reality. The Shanghai Library is the second largest library in China. It is a large public library that also functions as the leading resource library for the Shanghai university community, with exceptionally strong collections in the areas of science and technology. The city of Shanghai is a very westernized city in comparison with most of China, hence its nickname "China's window on the West".

I left Toronto very early on 28 October 2004 and flew to China via Vancouver, arriving on the following day at 1600 hours. China is $13 \mathrm{~h}$ ahead of Toronto, so night turns into day, and I had terrible jet lag for almost the first 2 weeks of my stay. The flight from Vancouver was wonderful. We flew up the coast of British Columbia, along the mountains of Alaska, over the Aleutian Islands, past eastern Russia and Korea, over Japan, and finally over the China Sea and straight down into Shanghai.

The first thing I noticed about Shanghai was the huge number of people. There are people everywhere. Shanghai is a city of 17 million, in an area roughly the size of Toronto. It is crowded everywhere, seemingly all the time - the airport, the streets, the intersections, the subway, and all the department stores and markets and shopping areas. There is severe gridlock, and there are literally millions of bicycles, large "cargo" tricycles, and motorcycles all over the sidewalks as well as the roads.

The second thing was the poor air quality. This was hard to miss and is at least partly the result of the extensive construction taking place all over the city. Shanghai is changing at a very rapid rate. Old areas are being demolished, and huge high rises and skyscrapers are going up in their place. It's very exciting to see, but it makes for a lot of dust!

The first really exciting thing for me was seeing actual Chinese characters denoting Shanghai Airport. Then I began to realize that everything was written in Chinese characters (of course!), and it sounds silly, but that was a huge adjustment for me. I'd never been to a country where there was

H. Michael. Gerstein Science Information Centre, University of Toronto Libraries, 9 King's College Circle, Toronto, ON M5S 1A5, Canada (e-mail: helen.michael@utoronto.ca). absolutely no chance of deciphering anything written. I was totally illiterate.

Getting around the city was best done by taxi. A taxi anywhere seemed to cost only about CAN\$4.00. (China is not expensive for Canadians.) This worked well for tourist sites, but there was a problem with lesser-known places. The taxi drivers could not read my Pinyin-transliterated map, and therefore it was necessary to have two - one in Pinyin, one in Chinese - so that we could put them together to figure out the location of my destination. One was then at the mercy of the taxi driver, and I never travelled anywhere without the hotel business card, so as to be sure of getting home.

\section{Description of the library}

My first impressions of the Shanghai Library made me want to cry. The building is lovely, solid as a rock, with 32 beautiful reading rooms and substantial, well-made furniture. Everything is spotless and sparkling, and the books are all tidy on the shelves. This is, of course, because there is an army of staff — 900 in total, 200 cleaning staff alone! There is seating for more than 3000 people, and there are two exhibition halls, two large lecture halls, and six seminar rooms. Retrieval of most of the 48 million items is done by the staff, since the stacks are closed. (There is a separate circulating collection of 100000 items, and all the most recent material throughout the reading rooms is directly accessible.)

To request retrieval, the user must find the item record in the Internet Public Access Catalogue (IPAC) and enter a request. The user is then given a retrieval number and waits up to 30 or more minutes for the item to appear. Items are sent down from all areas of the stacks on a computerized bookcarrier system, consisting of about 60 small "buckets" moving on rails at a rate of half a meter per second. As items are ready for the user, the retrieval number is posted electronically on a ceiling-high screen. The user must then claim the book, take it to a separate counter to request photocopying, if required, and return it to be reshelved.

\section{Resources and staffing}

There are more than 48 million items in the Shanghai Library and many electronic resources. Because these are not all networked, it is not easy to be sure what is really avail- 
able. Everything published in Shanghai is purchased by the Shanghai Library and then other Chinese material is purchased as budgets permit. Foreign language material is chosen from the lists of a book import-export company that arranges all purchases. The 32 reading rooms reflect the breadth of material that is collected (e.g., Chinese natural sciences, industrial documents, genealogy, business information, foreign publications). A wide variety of services are offered. There are extensive search and consultation services, including many for business and industry. There are a few that seem strange to the westerner (e.g., "house property management services").

The Shanghai Library, like most other establishments in the city, is extremely well staffed by western standards. There is a sense of relaxation among the staff, which is striking to the westerner. However, it is quite normal to see staff members of all ages literally running to get whatever it is that the user needs. All staff members wear a uniform consisting of dark jacket, slacks, and (optional) vest, provided by the library, and a white shirt. The staff also wear photo ID.

I met the director of the library, Dr. Wu Jianzhong, in the eastern visitors' room, which is the one used for visitors from the West. The room is full of dark-red wooden chairs decorated with dragons and flowered screens and cabinets. Dr. Wu completed his library Ph.D. at the University of Aberystwyth in Wales and speaks excellent English. It seems there is still a strong paternalistic relationship between the library employees and the director, though not as strong as in earlier times, when the director was required to give his approval to staff marriages! Even quite recently it seems that the library was responsible for ensuring that all retirees were supplied with decent housing. Salaries are not set by the director, so this is not an issue. A canteen service is provided for staff, which is very inexpensive and must be heavily subsidized (I spent approximately CAN $\$ 20$ on lunches over the span of 4 weeks). Lunch is from 1130 to 1300 hours, and employees often turn down the lights and sleep on their desks, if they are out of the public eye.

There were always uniformed army guards in the lobby, but they were very approachable. On one of the few rainy days, they stood at the top of the steps and handed out open plastic bags for people to put their umbrellas and raincoats in so that water would not get all over the foyer.

\section{The work experience}

\section{Patents, standards, and technical reports}

During the first 2 weeks, I worked in the Reading Room for Patents, Standards, Technical Reports, Abstracts and Indexes. Here are a great variety of print, CD-ROM, and networked resources, some on a LAN, a few available via the Web. Most are familiar, but accessed with a Chinese interface.

Since I can neither speak nor read Chinese, the staff was initially not really sure what I should do. We eventually settled on a system: someone in the department would translate incoming e-mail questions into English, I would answer them in English, and she would translate the answers back for the user. This arrangement worked quite well. The younger staff spoke reasonably good English, so I was able to ask for help with the computer screens, which were the biggest problem for me.

In fact, the computer screens were a huge challenge, because they were mostly in Chinese and totally unfamiliar. Most people search the databases by entering the Pinyin transliteration, since the keyboards show the western alphabet. The results might display in Chinese or western script. I resorted to drawing diagrams of the screens I used most frequently to help me know what I was searching and how to navigate. I was told that most people use Pinyin to input a query, but there are actually several different input methods, and some people use a system based on character strokes for which they need a good grasp of the linguistic radicals. The arrangement of entries in things like dictionaries and telephone books is still something I'm not sure about, but it may be based on the number of strokes in a character.

I'm told there are 50000 characters in Chinese, and at least 5000 characters must be learned just for basic purposes like reading the newspaper.

\section{Document supply centre}

I spent the next 2 weeks in the Document Supply Centre, a fairly new service consisting of document supply and interlibrary loan, literature searching, translation service, and clipping service. Most of the work in this centre is fee based. The translation service provides translation for about 15 languages. A member of the document services team farms out the jobs to a roster of translators, many of whom work for the Chinese Academy of Sciences or are retired researchers. Charges depend on the language being translated and the number of Chinese characters involved in the translation. English and Japanese translations are the most affordable.

The search and consultation service consists of a literature search - mostly using Chemical Abstracts, Engineering Index, or another STM database - and the supply of selected articles. The staff is also involved in a project funded by the municipal government to set up an archival site for SINOPEC, the China Petroleum and Chemical Corporation. Similar knowledge management projects are being undertaken for other commercial customers.

I was assigned to the Document Services Team. I searched for items in the IPAC so that they could be retrieved for photocopying or scanning. Many of the requests came from university libraries around China, since the Shanghai Library has such an extensive collection. The library uses OCLC for interlibrary loan, and either fax, Ariel, or China Post Express Mail Service to deliver items, which may also be sent as e-mail attachments whenever possible. Records are added regularly to the OCLC database; the availability of ISSN and ISBN numbers for these records is a boon to the non-Chinese searcher!

Copying rules appear to be less stringent than in Canada. It appears that so long as a copy is not made for commercial purposes, it can be as extensive as the patron wishes, so sometimes whole books are copied. This is seen as preferable to loaning an item, which is done only if there are two additional copies in the library.

Borrowing and loaning items that have to be returned is considered to be somewhat problematic. There is a reluctance to send out items that might get lost and a reluctance to borrow items that, if lost, might have to be paid for later. 
This stems from the recent loss of a Library of Congress book that cost the Shanghai Library dearly to replace because of the unfavourable exchange rate. Most items come from the China National Library, other Chinese universities (in particular Tsinghua University in Beijing), the Japan National Diet Library, and various North American libraries, including the Canada Institute for Scientific and Technical Information.

In addition to working in the units described, I was given orientation to most of the other areas in the library, and I had discussions with the staff in the foreign languages section. From these discussions I learned that the national Chinese Library Classification is used for book classification, and OCLC cataloguing is configured to map to the appropriate numbers. The scheme is somewhat similar to LC in its layout. Prior to 1949, a Chinese version of the Dewey Decimal Classification System was used for book classification.

\section{Other libraries}

Cooperation among libraries of all kinds is stated in the goals of the Shanghai Municipal Government, and there are several good examples of the sharing of resources. The Shanghai Information Resources Network (SIRN) has 31 member libraries, including most of the universities in the Shanghai area, and is concerned with implementing and upgrading the technology associated with online resources and connectivity.

The China Academic Library and Information System (CALIS) is a nation-wide consortium consisting of 100 of the 1400 university libraries in China. Members are selected by the government and focus on bibliographic searching and interlibrary loan.

\section{Jiaotong University Library}

During my stay in Shanghai I had the opportunity to visit several other libraries. Jiaotong University (http://www.lib. sjtu.edu.cn/english/) has an excellent reputation for science and technology throughout China and has four separate campuses. The central campus library, which I visited, has a collection of 2.7 million volumes, with subscriptions to 4000 print journals, $50 \%$ of which are in Chinese, $50 \%$ in a foreign language. In the past, these consisted of Russian, German, Japanese, and English titles. There is a current shift towards English titles.

Electronic resources account for about $35 \%$ of the acquisitions budget, and they number 15000 titles. There are 40 data systems (e.g., Web of Knowledge) supplying more than 200 databases. Many of these would be familiar to our users in Canada; others are of Chinese origin. Jiaotong University provides a mirror site for Elsevier (one of only two in China) and in this capacity serves 200 libraries. Students have free access to all the databases and to the Internet from the university IP range. It seems that free access to resources is not common among university libraries. Remote access is possible via a proxy, which must be set up by the Network Centre, and appears to be very strictly controlled.

The library has 200 staff members, about a quarter of whom are professionally trained. Priorities for hiring professional staff are library training, computer training, and Eng- lish language skills. Computer training is beginning to take over from library training as the most important skill set. Each librarian is assigned a subject area, which includes responsibility for the relevant databases. In this capacity the librarian must check the database daily for functioning; deal with the provider as necessary; write up instructional fliers for the users; and provide training in the lab in the form of a structured PowerPoint presentation listing the features of the database being taught and a case study.

The library takes a lead role within CALIS (see above). CALIS provides cataloguing records to its members and interlibrary loan and document delivery based on the system designed by the Tsinghua University Library. A virtual reference project is under way, sponsored by CALIS, which will use software developed inhouse. The use of CrossLink is being investigated as a link resolver.

\section{Some observations and conclusions}

There are, of course, many differences between libraries in China and those in Canada, but at least some of these differences can be seen as the result of the larger staffs employed in China. The Shanghai Library has much more staff than would be found in a similar library in the West. As a result, the library is able to provide a broad range of services for its users, of the kind we expect users to manage themselves. At the Shanghai Library, all copying is done by staff; almost all retrieval is done by staff; and staff (often two at once) check library cards at reading room entrances. Uniformed guards are on hand both in and out of the library and can be approached for assistance. Many library staff are available to answer questions in all areas.

The Shanghai Library has an exceptional collection of which it is justly proud. Items are not lent if they may get lost and are difficult to replace (e.g., on interlibrary loan), and the users are not permitted to enter the stacks. This care of the collection is accompanied by more paperwork than we would perhaps feel necessary; for example, when an item is taken from the stacks, its details are manually recorded in a notebook, and when it is returned it is checked off. This speaks to the large staff available and is the kind of function that we have either abandoned or automated.

The Shanghai Library is eager to involve librarians from outside China in its work. To this end, it has invited me to assist with e-mail reference when a health science question is involved. Similar assistance in different subject areas has been provided by other program participants and seems to have worked well.

Regarding future visits and the content of the program, it must be said that the computer screens are a huge challenge for non-Chinese speakers. Some basic knowledge of Chinese, acquired before leaving Canada, would be useful, both in and out of the library.

A final word must go to the Shanghai Library staff, who treated me with the utmost hospitality during my visit. Their patience and, in fact, the patience and friendliness of all the people I met in Shanghai means I would have no hesitation in recommending such a visit to other colleagues fortunate enough to have such an opportunity. 